\title{
Feasibility of Artificial Neural Network in Civil Engineering
}

\author{
Vikash Singh"1, Samreen Bano², Anand Kumar Yadav³, Dr. Sabih Ahmad ${ }^{4}$ \\ 1,2,3 M.Tech Scholar, Department of Civil Engineering, ${ }^{4}$ Associate Professor, Department of Civil Engineering \\ 1,3Madan Mohan Malaviya University of Technology, Gorakhpur, Uttar Pradesh, India \\ 2,4Integral University, Lucknow, Uttar Pradesh, India
}

\begin{abstract}
How to cite this paper: Vikash Singh | Samreen Bano | Anand Kumar Yadav | Dr. Sabih Ahmad "Feasibility of Artificial Neural Network in Civil Engineering" Published in International Journal of Trend in Scientific Research and Development (ijtsrd), ISSN: 2456-6470, Volume-3 | Issue-3, April 2019, pp.724728, URL: http://www.ijtsrd.co $\mathrm{m} /$ papers/ijtsrd229 85.pdf

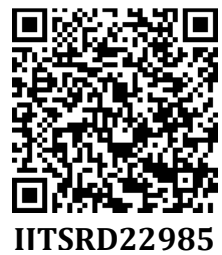

Copyright (C) 2019 by author(s) and International Journal of Trend in Scientific Research and Development Journal. This is an Open Access article distributed under the terms of the Creative Commons

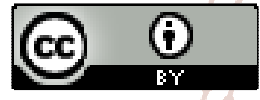
Attribution License (CC BY 4.0) (http://creativecommons.org/licenses/ by $/ 4.0$ )

\section{INTRODUCTION}

Artificial Neural Network (ANN) is a form of artificial intelligence which attempt to mimic the function of the human brain and nervous system. An ANN is an informational system simulating the ability of biological neural networks by interconnecting many simple neurons. Although developing an analytical or empirical model is viable in some simplified situations, most developed process is multifaceted, and therefore, models that are less general, more realistic and less expensive than the analytical models are of interest. It is more beneficial than regression process because it have more capacity to deal multiple outputs and responses while regression model is able to deal with only one response. The goal of this field is to explore how to emulate and implement some of the intelligent function of human brain, so that people can develop technology products and establish relevant theories.

In recent years, the improvement of the genetic algorithm introduced many new mathematical tools and absorbed civil engineering as the latest achievement of applications. We can expect, along with the computer technology, the genetic algorithm in civil engineering application will be more general and more effective. Kingston et al. (2005b) stated that if "ANNs are to become more widely accepted and reach their full potential...., they should not only proved a good fit to the calibration of validation data, but, but the prediction should also be plausible in terms of the relationship modelled and robust under a wide range of conditions" and that "while ANN validation against error alone may produce accurate predictions for situation similar to those contained in the training data, they may not be robust under different conditions unless the relationship by which the data were generated has been adequately estimated."

Recently artificial neural network (ANN) models have been widely applied to various relevant civil engineering areas such as geo-technical engineering, structural engineering, water resource engineering etc. In the field of civil engineering, many problems, especially in engineering design, construction management and decision making program were influenced by many uncertainties which could be solved not only in need of mathematics, physics and mechanic calculations but also depend on the experience of practitioners. Civil engineering students need to learn how to deliver practical sustainable solutions for the engineering projects. Thomson (2010) established that applied assessment and award techniques can be usefully used as teaching tools. Obonyo (2011) describe the deployment of an e-learning environment for construction courses based on enhancing virtual computing technologies using agent-based 
techniques. The proposed agent oriented methodology and resulting application organises construction knowledge into a structure that enables the students to undertake more selfdirected, systematic and scientific exploration. Flood (2008) applied artificial neural network to stimulate interest within the civil engineering research community for developing the next generation results show that this approach requires the design of some very sophisticated genetic coding mechanism in order to develop the required high order network structures and utilize development mechanism observed in the nature such as growth, self-organisation and multi-stage objective function. Neural networks research is artificial intelligence has recently provided powerful system that works as a supplement or a complement to such conventional expert system. It poses a number of attractive properties for modelling a complex mechanical behaviour or a system: universal function approximation capability, resistance to noisy or missing data, accommodation of multiple non linear variables for unknown interaction and good generalization capabilities.

In this paper, neural network are introduced as a promising management tool that can enhance current automation efforts in the civil engineering including its application in geo-technical engineering, structural engineering, traffic engineering and in construction management. Basic neural networks architectures are described and its applications in various field of civil engineering is also discussed. Future possibilities of integrating neural network and expert systems as a basis for developing efficient intelligent systems are described.

\section{Historical Background}

The history of neural networks can be divided into several periods: from when developed models of neural networks based on their understanding of neurology, to when neuroscience became influential in the development of neural networks. Psychologists and engineers also contributed to the progress of neural network simulations. Neurally based chips are emerging and applications to complex problem developing. Clearly, today is a period of transition for neural network technologies.

\section{ANN}

Artificial Neural Network (ANN) is a branch of computer science which involved in the research, design and application of intelligent computer. ANN is a massively parallel distributed processor a made up of simple processing units, which has a natural propensity for storing experimental knowledge and making it available for use (Haykin, 1999). It is an information processing paradigm that is inspired by the way biological nervous systems, such as the brain, process information. It is composed of a large number of highly interconnected processing elements (neurons) working in unison to solve specific problem. According to Michael Morzer of university of colorada, "The neural network is structured to perform nonlinear Bayesian classification". The performance and computational complexity of neural networks are mainly based on network architecture, which generally depends on the determination of input, output and hidden layer.

ANN development is based on the following rules (ASCE, 2000a):

1. Information processing occurs at many single elements called nodes, also referred to as units, or neurons
2. Signals are passed between nodes through connection links.

3. Each connection links has an associated weight that represents its connection strength.

4. Each node typically applies a non-linear transformation called an activation function to its net input to determine its output signals.

Learning in ANNs is generally divided into supervised and unsupervised (Masters 1993). In supervised learning, the network is offered with a historical set of model inputs and the equivalent output. The actual output of the network is compared with the desired output and an error is calculated. This error is used to adjust the connection weights between the model inputs and outputs to reduce the error between the historical outputs and those predicted by the ANN. In unsupervised learning, the network is only presented with the input stimuli and there are no desired outputs. The idea of training in unsupervised networks is to cluster the input records into classes of similar features.

\section{Architecture of Neural Network}

In general, an artificial neural network can be divided into three parts (da silva et al. , 2017) :-

1. Input Layer: -This layer gains information in the form of data, signals, features or measurements from external sources. These inputs are usually normalised within the limit produced by activation functions.

2. Hidden Layer: -These layers consist of no. Of neurons which are responsible for extracting patterns associated with the process or system being analyzed. These layers perform most of the internal processing from a network.

3. Output Layers: -This layer also consists of no. of neurons and thus is responsible for producing and presenting the final networks outputs, which results from the processing performed by the neurons in the previous layer.

The main architecture of artificial neural networks considering the neuron deposition, as well as how they are interconnected and how its layer are composed, can be divided as follows:-

\section{A. Single-Layer Feed-forward Network: -}

This artificial neural network has only one input layer and corresponding only one output layer. Figure 1 show a simple-layer feed-forward network composed of ' $n$ ' inputs and ' $m$ ' outputs.

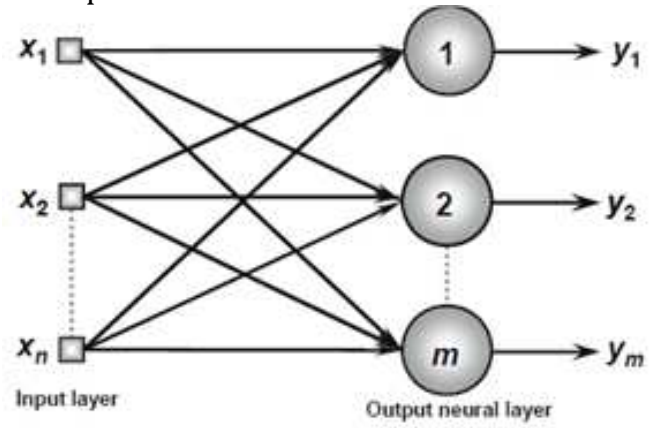

Figure 1 (Single-layer feed-forward network) ((da silva et al., 2017) 


\section{B. Multiple-Layer Feed-forward Network: -}

This artificial neural network has one or more hidden layer between input layer and output layers. It is generally used for complex problem like system identification, process control, optimization, and robotics and so on. Figure 2 shows a feed-forward network with multiple layers composed of one input layers with ' $n$ ' sample signals, two hidden neural layers consisting of ' $n 1$ ' and ' $n 2$ ' neurons respectively, and finally, one output neural layer composed of ' $\mathrm{m}$ ' neurons representing the respective output values of the problem being analyzed.

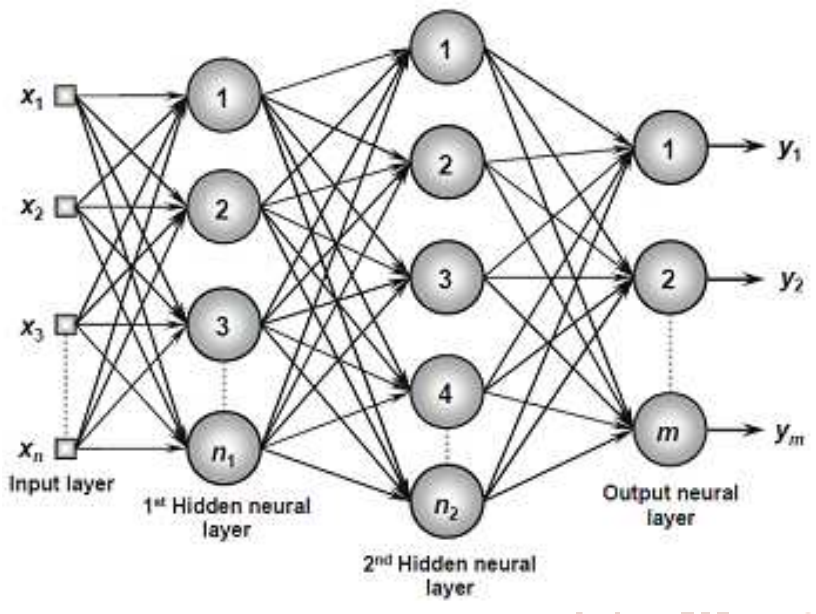

Figure 2 (Multiple-layer feed-forward network) (da silva et al., 2017)

\section{ANN Training}

The training process of a neural network consists of applying the required ordinate steps for tuning the synaptic weights and thresholds of its neurons, in order to generalize the solutions produced by its outputs (da silva et al., 2017). The primary goal of training is to minimize the error function by searching for a set of connection strengths and threshold values that cause the ANN to produce outputs that are equal are close to targets. The manner in which the node of ANN is structured is closely related to the algorithm used to train it. Some of the algorithm used ANN training include backpropagation algorithm, conjugate gradient algorithms, radial basis function, cascade correlation algorithm (Nagesh Kumar et al., 2004). All of these algorithms are briefly described in ASCE (2000a) with an exhaustive list of references.

\section{Application on ANN in Civil Engineering}

The first journal article on civil/structural engineering applications of neural networks was published by Adeil and Yeh (1989). Since then, a large number of articles have been published on civil engineering applications of neural networks. The great majority of civil engineering applications of neural networks are based on simple back propagation algorithm. One of the reasons for popularity of the neural network is the development of the simple error back propagation (BP) training algorithm (Rumelhart et al., 1986), which is based on a gradient-descent optimization technique.

\section{Study the behaviour of building materials:-}

Reinforced cement concrete posses complexities in their structural behaviour due to composite nature of the material and the mass and variety of factors that affect such behaviour. Current methods for the design and analysis of RCC are limited in scope and are approximate at best as they rely on the results of experimental tests, which are both costly and time-consuming to perform. The research personified by this document investigates the use of a branch of artificial intelligence known as Neural Network as a quick and reliable alternative to such experimental testing.

The construction used materials or mixture of materials with heterogeneous behaviour in the structure, which is difficult to establish a formula applies to various case encountered. With the help on ANN we can find out the different properties of materials like compressive strength of concrete according to different mixtures of concrete (Kim, 2005), slump value of concrete (Oztas et al., 2006), the value of the ultimate shear force in concrete beams and the value of ultimate strength $(\mathrm{Pu}, 2006)$ and other material properties like elastic modulus, position's ratio, ultimate strength and yield strength (Pandya and Shah, 2014). Also, using neural networks can perform behaviour's simulation of reinforced concrete at different ages and can help by macro calculating to model of the reinforcement -concrete's interface (Unger, 2009).

\section{In geo-technical engineering:-}

Since the early 1990s, ANNs have been applied successfully to almost every problem in geo-technical engineering. Classical constitutive modelling based on the elasticity and plasticity theories are unable to properly simulate the behaviour of geo-materials for reasons pertaining to formulation complexity, idealization of material behaviour and excessive empirical parameters (Adeil, 2001). Geotechnical properties of soils are controlled by factors such as mineralogy; fabric; and pore water, and the interactions of these factors are difficult to establish solely by traditional statistical methods due to their interdependence (Yang and Rosenbaum, 2002). Based on the application of ANNs, methodologies have been developed for estimating several soil properties including the preconsolidation pressure (Celik and Tan, 2005), shear strength and stress history swell pressure (Erzin 2007 and Najjar et al., 1996a), compaction and permeability (Agrawal et al., 1994; Goh, 1995b), soil classification (Cal, 1995) and soil density (Goh, 1995b).

Liquefaction during earthquake is one of the very dangerous ground failure phenomena that cause a large amount of damage to most civil engineering structures. This has attracted many researchers (Agrawal et al., 1997; Ali and Najjar, 1998; Ural and Saka, 1998) to investigate the applicability of ANNs for predicting liquefaction.

Other applications of ANNs in geo-technical engineering include retaining wall (Goh et al., 1995; Kung et al., 2007), dams (Kim and Kim, 2008), blasting (Lu, 2005), mining (Rankine and Sivakugan, 2005), rock mechanics (Gokceoglu et al., 2004), site characterisation (Basheer et al., 1996), tunnels and underground openings (Benardos and Kaliampakos, 2004; Lee and Sterling 1992) and geoenvironmental engineering (Shang et al., 2004).

\section{In Hydrology:-}

Artificial neural network have gained popularity in the field of hydrology because it shows it's evidence by the increasing number of papers on this topic. Flood and Kartam (1994, 1997) reviewed the application of ANNs to various branches of civil engineering. 
The problem of rainfall - runoff modelling has received the maximum attention by ANN modellers in hydrology. ANNs have achieved some success in stream flow prediction (time series), particularly when this are desired over a certain range of stream flow values. Aziz and Wong (1992) explained the use of ANNs for determining aquifer parameter values from normalized drawdown data obtained from pumping tests commonly referred to as the contrary problem in ground water hydrology. Yang et al. (1997) utilized an ANN to predict water table elevations in subsurface- drained farmlands. ANNs were used for estimating precipitation with limited success. While the articles reviewed in this paper on ANN applications in hydrology are not exhaustive, it is obvious that ANNs have made a significant impact in this area.

\section{In transportation engineering:-}

Artificial neural network for transportation infrastructural system must include system engineering techniques that will be sustainable for future years and maintained at acceptable levels. There are many reasonable factors currently impacting the transportation sectors, which requires careful system consideration such as; the high capital cost of design and construction, change to the legislations and the impact of the increase in demand and usage of transport infrastructure.

Some of the infrastructure issues solved with neural network consists of: identifying traffic problems to improve its fluency (Zhang, 1997), an advanced decision support system for management actual traffic in areas where are sites in working (Jiang and Adeli, 2004), detecting incidents on highway traffic to improve transport system (Adeli, 2005), predict cracks in flexible road structures (Owusu-Ababio, 1998), and predicting dynamic modulus of hot mix asphalt (Ceylan, 2008).

\section{In construction Management:-}

Neural Networks are introduced as a promising management tool that can enhance current automation efforts in the construction industry, including its applications in construction engineering. Construction engineering is a professional discipline that deals with the designing, planning, construction, and management of infrastructures such as highways, bridges, airports, railroads, buildings and dams. It is used in construction engineering and management is for prediction, risk analysis, decision-making, resources optimization, classification and selections.

Margaret W. Emsley et al. (2002) developed Neural Network cost models using data collected from nearly 300 building project. Basically It is based on linear regression methods can be used as a benchmark for evaluation of the neural network models. The outcome showed that nonlinearity in the data can be easily solved by the neural networks. Murat Gnaydm et al. (2003) developed and test a model of cost estimating for the structural systems of RCC building through neural networks. It provides the informed decisions at the early phases of the design. Cost and design data from thirty projects were used for training and testing neural network methodology with eight design parameters utilized in estimating the square meter cost of reinforced concrete structural systems of 4-8 storey residential buildings in Turkey, an average cost estimation accuracy of $93 \%$ was achieved.

\section{Conclusion}

It is clear that ANNs have been successfully applied to many civil engineering areas like prediction, decision-making, risk analysis, resources optimization, classification and selections etc. Based on the results, it is that ANNs perform better than other conventional methods. In civil engineering many problems are very complex and not well understood. Most of the mathematical models fail to solve such complex behaviour. ANNs are based on only input and output data by which model can be trained easily. ANNs can always be updated to obtain better output by showing new training examples as new data become available.

Thus ANNs have a number of significant results that make them a powerful and practical tool for solving many problems in the field of civil engineering and are expected to be applicable in future.

\section{References}

[1] A. Öztaş, M. Pala, E. Özbay, E. Kanca, N. Çağlar, and M. A. Bhatti, "Predicting the compressive strength and slump of high strength concrete using neural network," Construction and Building Materials, vol. 20, no. 9, pp. 769-775, 2006.

[2] Adeli, H. (2001). "Neural networks in civil engineering: 1989-2000." Computer-Aided Civil and Infrastructure Engineering, 16(2), 126-142.

[3] Agrawal, G., Weeraratne, S., and Khilnani, K. (1994). "Estimating clay liner and cover permeability using computational neural networks." Proceedings of the 1st Congress on Computing in Civil Engineering, Washington.

[4] Agrawal, G., Chameau, J. A., and Bourdeau, P. L. (1997). "Assessing the liquefaction susceptibility at a site based on information from penetration testing." Artificial neural networks for civil engineers: Fundamentals and applications, N. Kartam, I. Flood, and J. H. Garrett, eds., New York, 185-214.

[5] Ali, H. E., and Najjar, Y. M. (1998). "Neuronet-based approach for assessing liquefaction potential of soils." Transportation Research Record No. 1633, 3-8.

[6] ASCE. (2000). "Artificial neural networks in hydrology. I: Preliminary concepts." J. Hydrologic Engineering, 5(2), 115-123.

[7] Aziz , KFV Wong, 1992. Neural network approach to the determination of aquifer parameters, Ground Water, 30(2), pp. 164-166.

[8] Basheer, I. A., Reddi, L. N., and Najjar, Y. M. (1996). "Site characterization by neuronets: An application to the landfill sitting problem." Ground Water, 34, 610-617.

[9] Benardos, A. G., and Kaliampakos, D. C. (2004). "Modeling TBM performance with artificial neural networks." Tunneling and Underground Space Technology, 19(6), 597-605.

[10] Cal, Y. (1995). "Soil classification by neural-network." Advances in Engineering Software, 22(2), 95-97.

[11] Celik, S., and Tan, O. (2005). "Determination of preconsolidation pressure with artificial neural network." Civil Engineering and Environmental Systems, 22(4), 217-231. 
International Journal of Trend in Scientific Research and Development (IJTSRD) @ www.ijtsrd.com eISSN: 2456-6470

[12] Ceylan H., Gopalakrishnan K., Kim S. Advanced Approaches to Hot-Mix Asphalt Dynamic Modulus Prediction, pp. 699-707, 2008.

[13] Da Silva et al. (2017) "Artificial Neural Networks". Springer International Publishing Switzerland 2017. DOI 10.1007/978-3-319-43162-8_2

[14] D Nagesh Kumar, K Srinivasa Raju, T Sathish. 2004. River flow forecasting recurrent neural network, Water Resources Management, 18(2), pp-143-161.

[15] E. Obonyo, "An agent-based intelligent virtual learning environment for construction management," Construction Innovation, vol. 11, no. 2, 2011.

[16] Erzin, Y. (2007). "Artificial neural networks approach for swell pressure versus soil suction behavior." Canadian Geotechnical Journal, 44(10), 1215-1223.

[17] Flood, I., and Kartam, N. (1994). "Neural networks in civil engineering I: Principles and understanding." Journal of Computing in Civil Engineering, 8(2), 131148.

[18] Goh, A. T. C. (1995b). "Modeling soil correlations using neural networks." Journal of Computing in Civil Engineering, ASCE, 9(4), 275-278.

[19] Goh, A. T. C. (1995a). "Empirical design in geotechnics using neural networks." Geotechnique, 45(4), 709-714.

[20] Gokceoglu, C., Yesilnacar, E., Sonmez, H., and Kayabasi, A. (2004). "A neuro-fuzzy model for modulus of deformation of jointed rock masses." Computers and Geotechncis, 31(5), 375-383.

[21] Gunaydın H. Murat , Zeynep Do S.gan "A neural network approach for early cost estimation of structural systems of buildings" International Journal of Project Management vol.22 ,2004,595-602

[22] Haykin, S., Neural Networks, A Comprehensive Foundation, second ed. Prentice-Hall, Englewood Cliffs, NJ, 1999.

[23] I. Flood, "Towards the next generation of artificial neural networks for civil engineering," Advanced Engineering Informatics, vol. 22, no. 1, pp. 4-14, 2008.

[24] Jiang X., Mahadevan S. Bayesian Probabilistic Inference for Nonparametric Damage Detection of Structures, J. of Eng. Mechanics (C) ASCE, pp. 820-832, 2008.

[25] Kim D.K. Neuro-control of fixed offshore structures under earthquake, Engineering Structures 31, pp.517522, 2009.

[26] Kim, Y., and Kim, B. (2008). "Prediction of relative crest settlement of concrete-faced rockfill dams analyzed using an artificial neural network model." Computers and Geotechnics, 35(3), 313-322.

[27] Kingston, G. B., Maier, H. R., and Lambert, M. F. (2005b). "Calibration and validation of neural networks to ensure physically plausible hydrological modeling." Journal of Hydrology, 314(2005), 158-176.

[28] Kung, G. T., Hsiao, E. C., Schuster, M., and Juang, C. H. (2007). "A neural network approach to estimating deflection of diaphram walls caused by excavation in clays." Computers and Geotechnics, 34(5), 385-396.

[29] Lee, C., and Sterling, R. (1992). "Identifying probable failure modes for underground openings using a neural network." International Journal of Rock Mechanics and Mining Science \& Geomechanics Abstracts, 29(1), 4967.

[30] Lu, Y. (2005). "Underground blast induced ground shock and its modeling using artificial neural network." Computers and Geotechnics, 32(3), 164-178.

[31] Margaret W. Emsley*, David J. Lowe, A. Roy Duff, Anthony Harding And Adam Hickson"'Data modelling and the application of a neural network approach to the prediction of total construction costs," Construction Management and Economics .20,2002,465- 472

[32] Masters, T. (1993). Practical neural network recipes in C++, Academic Press, San Diego, California.

[33] Najjar, Y. M., Basheer, I. A., and McReynolds, R. (1996a). "Neural modeling of Kansan soil swelling." Transportation Research Record, No. 1526, 14-19.

[34] P. Thompson, "Teaching sustainability in civil engineering using Ceequal," Proceedings of the Institution of Civil Engineers: Engineering Sustainability, vol. 163, no. 4, pp. 209-217, 2010.

[35] Pandya D., Shaha D. Experimentation and Its Prediction of Process Parameters Effects on Elongation in Tensile Test of AISI 1008 Steel Using ANN Model, Procedia Technology 14, pp. 282 - 289, 2014.

[36] Pu Y., Mesbahi E. Aplication of ANN to evaluation of ultime strength of steel panels, Engineering Structures 28, pp. 1190-1196, 2006.

[37] Rankine, R., and Sivakugan, N. (2005). "Prediction of paste backfill performance using artificial neural networks." Proceedings of the 16th International Society for Soil Mechanics and Foundation Engineering Osaka, Japan, 1107-1110.

[38] Rumelhart, D. E., Hinton, G. E., \&Williams, R. J." Learning internal representations by error propagation" 1986,Chap.8,.318-362

[39] Shang, J. Q., Ding, W., Rowe, R. K., and Josic, L. (2004). "Detecting heavy metal contamination in soil using complex permittivity and artificial neural networks." Canadian Geotechnical Journal, 41(6), 1054-1067.

[40] Unger J.F. and C. Konke (2009). Neural networks as material models within a multiscale approach. Computers and Strructure 87(19-20), 1177-1186.

[41] Ural, D. N., and Saka, H. (1998). "Liquefaction assessment by neural networks." Electronic Journal of Geotechnical Engineering, http://www.ejge.com/Ppr9803/Ppr9803.htm

[42] Yang, Y., and Rosenbaum, M. S. (2002). "The artificial neural network as a tool for assessing geotechnical properties." Geotechnical Engineering Journal, 20(2), 149-168.

[43] Yang, S O Prasher, R Laroix, S Sreekanth, NK Patni, LMase. 1997. Artificial neural network model for sub surface drained farmland, Journal of Irrigation and Drainage Engineering Divisions, ASCE, 123(4), PP. 285292.

[44] Yeh I.-C. "Modeling Of Strength Of High-Performance Concrete Using Artificial Neural Networks" Cement and Concrete Research, Vol. 28, No. 12, 1998; 1797-1808. 